
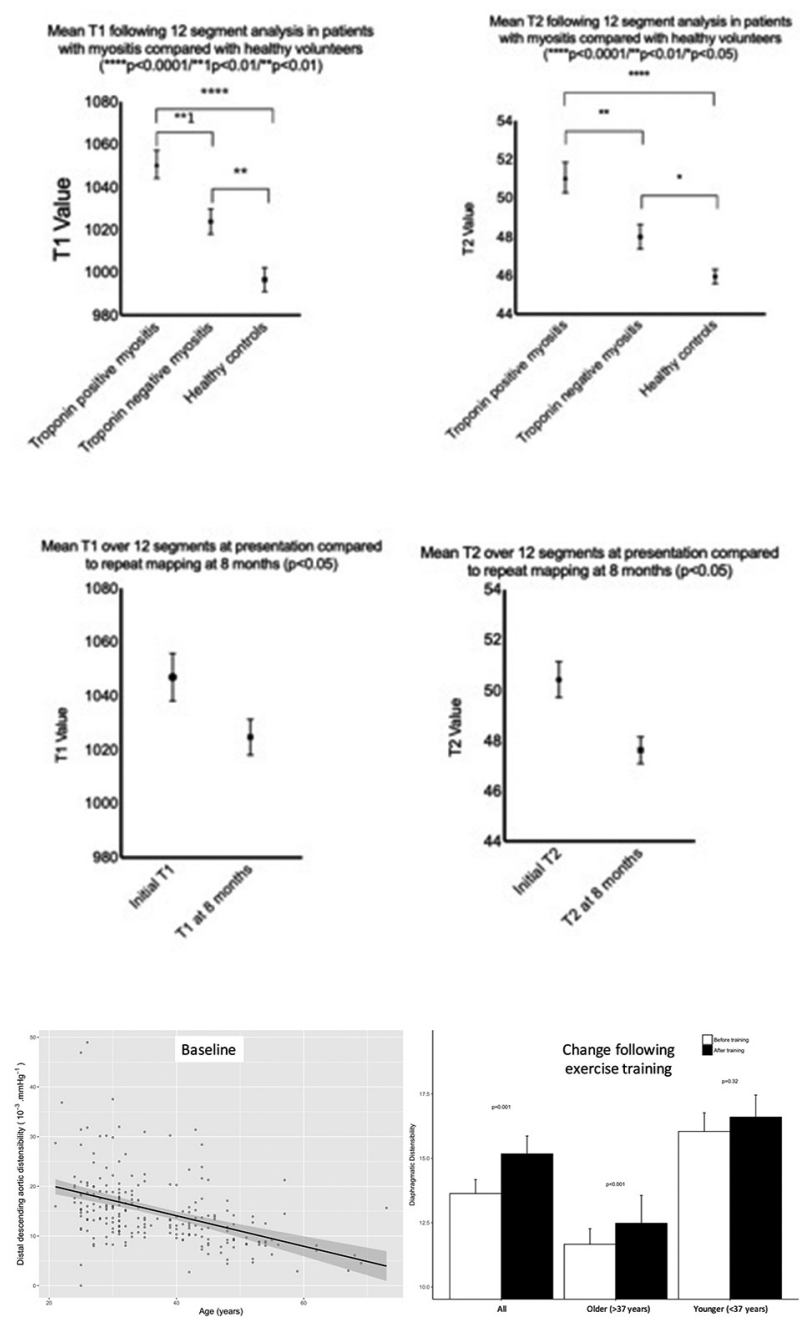

Abstract 11 Figure 1 Age and distal descending aortic distensibility before training (left), and the change with training (right)

Background Ageing is strongly associated with aortic stiffening, contributing to increased cardiovascular risk even in healthy individuals. Aortic stiffness is reduced in lifelong athletes, but whether training in novice runners can modify this process remains unclear. We hypothesized that exercise training for a first-time marathon would have beneficial effects on the agerelated increase in aortic stiffness.

Methods Untrained healthy volunteers were recruited prior to starting training for the London Marathon. Assessment pretraining and two weeks post-marathon included central (aortic) $\mathrm{BP}$ (cBP), and phase contrast $1.5 \mathrm{~T}$ CMR in the ascending (Ao-A) and descending thoracic aorta at two levels (pulmonary artery bifurcation and diaphragm - Ao-P and Ao-D). Aortic distensibility and beta-stiffness $(\beta, \quad$ a pressure-independent measure) were measured and correlated with chronological age at baseline to derive biological aortic age before and after training. Data are mean changes (95\% confidence intervals).

Results 139 first-time marathon completers (age range 21-69, $50 \%$ male) had assessment pre-training and 2 weeks post-marathon completion. As expected, increasing age decade was associated with decreasing distensibility by $2.3,1.9$ and $3.1 \times$ $10^{-3} \mathrm{mmHg}^{-1}$ for the Ao-A, Ao-P, and Ao-D respectively (partial $\mathrm{r}=0.4-0.5$ ), figure 1 .

Training decreased cSBP and CDBP by 4 (2.5-5.3) and $3 \mathrm{mmHg}(1.6-3.6)$, Table 1. With training, descending
Abstract 11 Table 1 Changes in central (aortic) blood pressure and aortic stiffness before and after exercise training

\begin{tabular}{|c|c|c|c|c|c|}
\hline \multirow[b]{2}{*}{ Central SBP (mmHg) } & \multicolumn{2}{|c|}{ Baseline } & \multicolumn{2}{|c|}{ Follow-up } & \multirow{2}{*}{$\frac{\mathbf{p}}{<0.001}$} \\
\hline & 110 & $(102,121)$ & 106 & $(100,114)$ & \\
\hline Central DBP (mmHg) & 76 & $(72,81)$ & 74 & $(69,78)$ & $<0.001$ \\
\hline \multirow{2}{*}{\multicolumn{6}{|c|}{$\begin{array}{l}\text { Distensibility }\left(\times 10^{-3} \text {. }\right. \\
\left.\mathrm{mmHg}^{-1}\right)\end{array}$}} \\
\hline & & & & & \\
\hline Ascending & 8.63 & $(5,11)$ & 8.45 & $(6,12)$ & 0.14 \\
\hline Proximal Descending & 8.52 & $(6,12)$ & 9.06 & $(6,13)$ & 0.009 \\
\hline Diaphragmatic & 13.63 & $(11,18)$ & 15.17 & $(12,21)$ & 0.001 \\
\hline \multicolumn{6}{|l|}{ Descending } \\
\hline \multicolumn{6}{|l|}{ Beta-stiffness } \\
\hline Ascending & 2.88 & $(2.48,4.18)$ & 3.12 & $(2.38,4.28)$ & 0.60 \\
\hline Proximal Descending & 3.12 & $(2.42,4.33)$ & 2.94 & $(2.28,4.03)$ & 0.07 \\
\hline Diaphragmatic & 2.02 & $(1.69,2.34)$ & 1.96 & $(1.62,2.3)$ & 0.02 \\
\hline Descending & & & & & \\
\hline
\end{tabular}

aortic distensibility increased at both Ao-P and Ao-D levels (by $9 \%, p=0.009 \%$ and $17 \%, p=0.001$ ), whilst unchanged in the ascending aorta. This translated to a reduction in biological aortic age at Ao-P by $3.9(1.1-7.5)$ and Ao-D 4.5 years(1.8-8.2). $\beta$ decreased by $7 \%$ at the Ao-D level, $\mathrm{p}=0.02$. Participants with slower marathon running times (Ao-P partial r: $-0.20, \mathrm{p}<0.05$ ), and older age (figure 1) showed a greater increase in descending aortic distensibility with training.

Conclusions Training for and completing a marathon improves central blood pressure and aortic stiffness even in novice athletes. These changes are the equivalent to a $\sim 4$ year reduction in vascular age. These benefits were greatest in older, less fit individuals. ${ }^{1}$

\section{THIS ABSTRACT HAS BEEN WITHDRAWN}




\section{Abstracts}

13 THIS ABSTRACT HAS BEEN WITHDRAWN 